\title{
Cross-Cultural Perspectives on Personality and Values: A Case Study of Mongolian vs. Taiwanese Doctors and Nurses
}

\author{
Tain-Fung Wu \\ Asia University \\ Munkh-Ulzii Batmunkh \\ Asia University
}

Alex S. R. Lai

Asia University

\begin{abstract}
Personality and value have been considered significant indicators in predicting personal behavior. The Big Five models and Hofstede's frame are the major tools used to assess personality and values, and they appear in almost all cross-cultural studies of personality and values. The present study also recognizes the anthropological aspects of cultures. The purpose of the study is to examine the differences in the cross-cultural attributes of personality and value aspects in the populations of North and Southeast Asia. An empirical study was conducted using doctors and nurses of Mongolian and Taiwanese healthcare institutions. Doctors and nurses were the subject of this study as it is within hospitals that social behavior in terms of personality and values of individuals presents itself. According to social development and perceptions of values, populations of this study will have both identical and contradictory sides. This study allows us the opportunity to identify personality and value aspects of north and south Asian people. This study uses a structured telephone interview method. The authors believe that the results of the study will contribute to measuring personality and values within the perspective of cross-culture differences.
\end{abstract}

\section{INTRODUCTION}

This paper was written jointly by three authors with varying value systems, cultures, and occupations. Perceiving that personality and values diverge from culture to culture, the authors believe that cross-cultural studies are helpful in exploring cultural distinctions, which are empirically and academically crucial in discussing management and cultural anthropological issues. Dr. Tain-Fung Wu is an associate professor at Asia University, Taiwan. His specialty is the study and exploration of organizational behavior. As a renowned international scholar in culture studies, Dr. Wu teaches at two national universities in Taiwan. 
Munkh-Ulzii is a doctoral student at Asia University. He is a Mongolian who spent two years obtaining his master's degree in Taiwan. One of his future goals is to research the correlation between customer personality and values and customer satisfaction. The present study can provide the foundation for his prospective study. Mr. Alex Lai, a native Taiwanese, is the project team co-worker with Munkh-Ulzii. Currently, he is a legislator in the Taiwanese Government. He began his career in politics after receiving his master's degree from a university in the United States.

Dr. Wu once invited Munkh-Ulzii and Alex to a discussion about personality and value issues for a research project. The purpose of the meeting was to summarize the key benefits of the class of "Organizational Behavior." During the initial discussion it was clear that everyone had dissimilar personality and values, and that they had different viewpoints concerning cultural aspects. After the meeting they reached the agreement that their personalities and values diverged cross-culturally, this became the initial spark for writing this article.

According to the recent studies of anthropologic psychology, the diversity of the emerging global environment and the diversity of human psychology have played an increasingly important role in organizational management. Organizations are trying to boost their competitive edge through outsourcing cross-cultural teams. Globalization has also increased the needs for people from different cultural backgrounds to work together (Marrewijk, 2010; Walle, 2010).

So far, a number of studies have concentrated on investigating the cross-cultural impact of personality and values (Butcher, Lim, and Nezami, 1998; Katigbak, Church, Guanzon-Lapeña, Carlota, and del Pilar, 2002; Paunonen et al.,1996; Low and Shi, 2002; McCrae, 2009). Human behaviors are tightly interrelated to each other within a particular context, and they are connected to other personality traits and values. These conditions can lead to mismanagement of those who are culturally different. Ignoring or mishandling these differences can lead to low employee morale, which will in turn disrupt international co-operation, causing losses to the company in question. Not recognizing cultural differences can result in the failure of managers and organizations. When cultural differences are successfully managed in accordance to team members ' personality, a faster and better learning atmosphere within the organization can sustain competitive advantage (Hoecklin, 1996).

One systems of cultural management difference is called cultural intelligence. In terms of management and organizational behavior, studies indicate that cultural intelligence has become one of the most important issues in cultural anthropology. Those studies define cultural intelligence as the capability to interact with people from different cultural backgrounds (Roth, M. S. 1995; Tomas and Inkson, 2004; Lillis and Tian, 2010).

The same dimensions can be found in every culture and intercultural comparisons. In recent years studies have addressed questions such as: Are North Asians more extraverted than Southeast Asians? (Terracciano and McCrae, 2006). In the era of increasing globalization, studies related to culture have focused on the impact of culture and personality of employees on a company's strategy, which merges cross-national boundaries (Pratt, Mohrweis, and Beaulieu, 1993). Due to the accelerating expansion of international relations (Iqbal and Elmallah, 1997) in the field of trade, humanity, and politics, as well globalization processes within social and ecological frameworks, studies have turned their attention from the cross-cultural aspects of culture differences to value difference.

Generally speaking, the term culture consists of the following factors: traditional values, beliefs, ideas, customs, skills, arts, and language of a specific group in a given period. Thus, cross-cultural studies are concentrated in the difference of those factors in relation to laws, and 
economic and political frameworks. Respectfully, there is no postulate that the complexity of whole cultures should not be affected by history, economics, and politics (Zandpour et al., 1994; Geertz, 1973; Lillis and Tian, 2009; Lillis and Tian, 2010; Emery, Tian, and Witte, 2002). This statement, in fact, shows the problematic nature of culture in cross-cultural studies. As long as culture is a complex system, cross-cultural studies need a systems approach. One of the main researchers posits that:

Cross-cultural studies presuppose a systems approach, by which I mean that any element of the total system called 'culture' 'should be eligible for analysis, regardless of the discipline that usually deals with such elements. At the level of cultures, these are phenomena on all levels: individuals, groups, organizations, or society as a whole may be relevant (Hofstede, 1980, pp. 32).

Two decades earlier, organizations were concerned only with personality as their primary concern was the appointment of employees to a specific task. Even though this phenomenon still exists in many places, there are some modern firms that tend to be more concerned with adjustment issues in changing environments. Since managers are more concerned with an employee's ability to adapt to changing situations rather than his skills in performing a specific task, they are more concerned with how well an individual's personality and values match the organization's goals (Robbins and Judge, 2009).

Koltko-Rivera (2006), along with Lillis and Tian (2009), argue that from everyday life experience, people face a "them vs. us" survival instinct. It is a basic part of who and what we are. In order to overcome that, we need to discover the differences, but the basic needs of humanity are not much different. We all need food, shelter, love, kindness, something to believe in, and finally, acceptance (Maslow, 1968; Salier, 2009; Duncan and Blugis, in press in 2010).

In several cross-cultural studies used, Hofstede's culture dimension and Big-Five approach to the measurement difference of personality and values (Pratt et al., 1993). Peoples' values often explain attitudes, behaviors, and perceptions. Hofstede's culture dimensions have had a strong impact in assessing culture differences (Vitell, Nwachukwu, and Barnes, 1993). The components of culture have been used in wide contexts, across most of the behavioral science disciplines. For instance, in the field of management and marketing, it has been used to examine issues such as cross-cultural differences in attitudes and behaviors (Alden, Wayne, Hoyer, and Chol, 1993; Abrams, Ando, and Hinkle, 1998), organizational identification and employees turnover intentions, and to compare stereotypes across different cultures (Soeters, and Schreuder, 1988; Soutar, Grainger, and Hedges, 1999). It has also been used in the studies of advertisement (McCarty and Hattwick, 1992; Gregory and Munch, 1997), global brand strategies, and ethical decision making. While the western countries appear to be low in power distance, and as individualistic, the Asian countries such as Japan, Korea, Singapore, and Taiwan belong to the high power distance and low individualistic group. But in general, they have a high masculinity level (Chow, Harrison, McKinnon, and Wu, 2002).

Many studies that have examined culture dimensions have noted that a number of researches have addressed the issue of personality across cultures. The dispute about which system is best has continued for decades. It has become clear that the Big Five model is the most preferred. The Big Five model has consistently represented the most reliable system of personality measurement and job performance. The term Big Five, which includes the dimensions of Neuroticism, Extraversion, Openness to Experience, Agreeableness, and Conscientiousness are known as the 
Big Five Model (McCrae and John, 1992). According to McCrae and Costa (1990), personality dimensions are defined as individual differences in tendency to show consistent patterns of thoughts, feelings, and actions.

In this study we compared the differences of culture and personalities between Taiwanese and Mongolian healthcare institutions, as the representative population of the North and Southeast Asia. Although they are typical Asian countries, according to historical records, geographical location, and national identity issues, they have a potential gap in perception of culture and personality. Studies of management and geopolitical science argue that basing the collective identities of cultural differences have been involved development terms, of such as third-world and forth-world, with first world being used to refer to the western world, the second world the communist or post communist countries, while the third world historically refers to nations that gained their independence after World War 11, and the former African and Asian colonies of the European powers (Fanon, 1952; Battiste and James, 2002; Smith, 1999).

The Mongolians have maintained a nomadic life style for over a thousand years (Anonymous, 1240; Baabar, 2000). Due to the geographical aspects, the country located far from the sea. Mongolia has very harsh weather conditions during the year, which has challenged the nation to survive biologically and economically through the centuries (National Statistical Office of Mongolia (2010). Monthly Bulletin of Statistics).

The Twentieth-Century introduced Mongolia to urban culture, and the state gained prosperity under the regime of the Soviet Union, which ended in the 1990s. These of factors led the nation to be characterized culturally as a mixture of nomadic and western oriented lifestyles (Baabar, 2000; Bayarkhuu, 2010). On the other hand, Taiwan is totally different, historically, geographically and geopolitically. To be sure, many features of Taiwan's culture bear similarities with Chinese culture and tradition and it might be explained that Taiwan is predominantly influenced by Confucian-Chinese culture (Chong and Hoecklin, 2008). However, Taiwan is democratic, and has been Americanized since the second half of the twentieth Century (Bor, 2000; Emery, Tian, and Witte, 2002).

Two percent of Taiwan's population consists of aboriginal people, while the majority 98 percent are Han people who emigrated from Mainland China. It is interesting to note that, due to political problems hundreds of wealthy and noble Mongolians immigrated and settled in Taiwan at the beginning of the last century. Accordingly, they were appointed to high administrative positions of the Taiwan Government soon after settlement. Therefore, the authors were interested in whether there was any cultural identity between the majority and minority of Taiwan population. And, it raises a question - why the minority of the population was appointed to the administrative positions in a short period of time (Bor, 2000; Baabar, 2000; Sibuet and Hsu, 2004).

Studies of organizational anthropology revealed that, when people are faced with a nexus of relationship that they do not understand, they usually interpret it to others as "abnormal", "weird" or "wrong". Much effort and work has been dedicated to the field of cultural and organizational anthropological studies around the world, especially in the United States and European countries, as well as in another 56 nations (Kevin and Black, 1993; Schmitt, Allik, McCrae, and Benet-Martínez, 2007; Lillis and Tian, 2010). But, almost no international study has measured the cultural issues in Mongolia. Again, this is a consequence of the so called second and third world effect. Thus, people of the world do not know much about Mongolia. The only perception of the Mongols throughout the world is limited to Chinggis Khaan, who is still 
one of the best known leaders not only in Mongolia, but also throughout the world (Anonymous, 1240; Jackson, 2000; Bor, 2000).

Between the Sixteenth-Century and the Twentieth-Century, the Qing Chinese rule became more oppressive in Mongolia. The increasingly corrupted rulers exacted high taxes, exploited the peasants, and brutally punished the slightest offence or resistance. By this time the Mongolian nationalists, seeing the advance of the Bolsheviks (Russian communists), called on them for help. Consequently, they recaptured Ulaanbaatar - the capital city of Mongolia, with military assistance of the Bolsheviks. Afterwards, China reluctantly recognized the independence of Mongolia in 1917. With military and political support from communist Russia, the newly formed Mongolian government took power. In 1924 Mongolia became the world's second communist country, which practiced planned economy, mostly dependent on Moscow until the 1990s (Jackson, 2000; Bor, 2000; MunkhDalai, Zhang, and Huiping, 2007).

Today, Mongolia has a population of about three million people, with a territory of 1.6 million square kilometers. The country is located between Russia and China, which makes it a very important region that connects the trade and economic channel between Europe and Asia. The country is rich with energy and mineral resources such as coal, uranium, oil, gas, gold, and copper, which has the potential of sustaining the country for at least eighty years. Thus, the world pays attention to this country as one of the main energy and economic resources of the near future (National Statistical Office of Mongolia (2010). Monthly Bulletin of Statistics; World Bank. (2007). Mongolia Country Economic Memorandum; World Bank. (2010). Quarterly report).

Eventually, the authors would conclude that the geographical location of Mongolia, which is landlocked and far away from any ocean, made it almost impossible for outsiders to reach the country. If they chose access the land via path, they had to overcome the deserts and steppes, which continue for hundreds of miles without end. Second, the harsh weather makes it difficult for foreigners to survive in the country (Bronfenbrenner, 1979). Third, the years of communist governance closed the door of Mongolia to the rest of the world. Forth, after entering the market economy in the 1990s, the culture, personality, and behavior of the people of Mongolia has changed much and the globalization process has played an enormous role as well. However, the root of nomadic culture and tradition has remained almost unchanged.

The relationship between Mongolia and Taiwan started in 2000, by focusing on such fields as education, trade, economy, and health. The number of Mongolian students who are studying in Taiwan has rapidly increased. Nevertheless, under the current presidential governance of Taiwan, the bilateral relationship between Taiwan and Mainland China has been developing; there is still a notable gap in the political world. This is the main barrier in developing a mutual collaboration between Mongolia and Taiwan. Likewise, the authors believe that to develop trade and economies as well as humanitarian co-operation will be fruitful for expanding the bilateral relationship of the two countries. Identifying the cultural differences and similarities is crucial in building on the present achievements already established between the countries (Bor, 2000; Ochirt, E. (2010). [Interview with Zhang Yi Ming, Head of the Taipei Trade and Economic Representative Office in Ulaanbaatar]. The News Politics, cable news channel. Retrieved on October 26, 2010 from http://politics.news.mn/content/36068.shtml).

These are the reasons Mongolia has been chosen as the target population for this study with Taiwan. The culture of this population is very open to academic research. The authors are confident that the results of the study will benefit the development of cultural management, and business anthropological studies in Asia. Thus, the main purpose of the paper is to explore the 
differences of the Mongolian and Taiwanese cultures that are semi-westernized, in terms of value and personality aspects and vice versa.

In examining culture differences, studies usually select firms as a sample, rather than public institutions. The present paper puts forward the public sector as the sample population of the study. It can be explained that studies focus on choosing the population that is expected to have more dynamic characteristics in social life. For this reason, the authors chose to use the healthcare system as they have a high interaction with the population (John and Srivasta, 1999). This paper postulates several reasons for making these choices in population.

One of the active frontline social components is healthcare staff. Practically, healthcare staffs, such as doctors and nurses, have a responsibility to serve the public welfare; they diverge from country to country due to their social security, educational background, and national culture versus globalization. First, social security for the healthcare staff is very poor in Mongolia compared to the standard internationally. Average salary for doctors and nurses in Mongolian hospitals ranges from $\$ 150$ to $\$ 300$ USD per month, while Taiwanese average salary for doctors and nurses is $\$ 1,000$ to $\$ 4,500$ USD. The meager payment of the healthcare system makes the staffs of hospital unsatisfied with their social security (Chang, 2003). In the case of attending international conferences, doctors cannot afford their expenses, and have to rely on their foreign counterparts to fund their travel and living expenses (Toby, Bonnie, Jackie, Roland, and Brenda, 2003; Ogoh, 1986; Tsung, 2010). Surprisingly, they never go on strike for higher payment. Even though they suffer extremely low pay, the healthcare institutions in Mongolia operate normally.

The western-oriented education system has dominated the healthcare systems of both countries. Most of the healthcare staffs specialize in western medicine regardless of their culture of origin. Hundreds of students graduate annually as doctors, a few of whom specialize in traditional medicine (Tyus, Gibbons, Robinson, Twose, and Guyer, 2010). Finally, due to the globalization process, classification of the patients has changed from monotype to multi-type. During the second half of the last century, the gross number of foreign patients being served by hospitals was less than today. The tremendous increase in international travel, trade, as well as studies in abroad as the consequence of globalization have contributed to this (Bernhard, 2009). Therefore, the paper posits an assumption that, besides cultural impact, social welfare, educational orientation, and globalization process also influence the personality and values differently. Moreover, members of healthcare institutions are rarely subjects in studies such as cross-cultural differences (Elisabeth and Lise, 2001; Sabine, Chris, and Dierckx, 2010). Hence, doctors and nurses appear as the subjects who deal with the public ditto (Richard and Marjot, 1961). Consequently, we chose doctors and nurses of healthcare institutions both from Taiwan and Mongolia, as the sample population for this study.

\section{LITERATURE REVIEW}

\section{Personality}

Studies demonstrate the significant impact of cultural effect on human behavior and personality as opposed to the rest of those factors, be they biological, genetic, psychological or environmental (Schein, 1993; Schlereth, 1999; Erchak, 1998; Lillis and Tian, 2010). Since culture influences all aspects of being human, it involves either subjective or objective elements. While attitudes, values, beliefs, opinions, behaviors are subjective, clothes, food, accessories are objective factors (Triandis, 1972; Wright, 1994; McCrae and Costa, 2003; Lillis and Tian, 2010). Also, Mariampolski (2005) asserts that culture operates on both the tangible and intangible levels 
of human experience, which serves as the foundation for the personality. Geertz (1973) describes culture as follows:

The concept of culture I espouse....is essentially a semiotic one. Believing, with Max Weber, that man [sic] is an animal suspended in webs of significance he himself has spun, I take culture to be those webs and the analysis of it to be therefore not an experimental science in search of law but an interpretive one in search of meaning.

Definition of personality was established by Gordon Allport nearly seventy years ago. As he asserted, personality is the dynamic organization within the individual psychophysical systems that determines its unique adjustment to an environment (Trice and Beyer, 1993; McCrae, Herbst, and Costa, 2001; Robbins and Judge, 2009). Researchers argue which structure has been best continued for decades. Recently, it becomes clear that most dimensions could be described in terms of the following five factors (John and Srivastava, 1999): openness, conscientiousness, extroversion, agreeableness, neuroticism.

Individuals, who score high highly in openness, are generally open to experience, intellectually curious, appreciative of art, and sensitive to beauty. They tend to be, compared to closed people, more creative and more aware of their feelings. People with low scores on openness tend to have less conventional and more conservative interests (Robbins, and Judge, 2009).

Conscientiousness is a tendency to show self-discipline, act dutifully, and aim for achievement. The trait shows a preference for planned rather than spontaneous behavior. It influences the way in which we control, regulate, and direct our impulses. Conscientiousness includes the factor known as need for achievement (Joshua et al., 2004).

Extroversion is characterized by positive emotions, urgency, and the tendency to seek out stimulation and the company of others. Extroverts enjoy being with people, and are often perceived as full of energy. However, the introverts lack social exuberance. They tend to seem quiet, low-key, deliberate, and less involved in the social world (Schmitt et al., 2007).

People who exhibit to Agreeableness are generally considerate, friendly, generous, helpful, and willing to compromise their interests with others (Joshua et al., 2004). Agreeable people also have an optimistic view of human nature. They believe people are basically honest, decent, and trustworthy. While disagreeable individuals remain unconcerned with others' well-being, are less likely to extend themselves for other people (Schmitt et al., 2007; Robbins and Judge, 2009).

Neuroticism is the tendency to experience negative emotions, such as anger, anxiety, or depression. Those who score highly in neuroticism are emotionally reactive and vulnerable to stress. They are more likely to interpret ordinary situations as threatening, and minor frustrations as hopelessly difficult. These problems in emotional regulation can diminish the ability of a person scoring highly on neuroticism to think clearly or make decisions. At the other end of the scale, individuals, who score low in neuroticism, upset less easily and less emotionally reactive. They tend to be calm, emotionally stable, and free from persistent negative feelings (Lazarus and Folkman, 1984; Schmitt et al., 2007; Robbins and Judge, 2009).

\section{Values}

Studies demonstrate that the anthropological approach is a very effective way to assess the impact of culture in research and development projects (Peters and Waterman, 1982; Morden, 1999; Lillis and Tian, 2010). According to Mariampolski (2005), culture is important as a 
heuristic principle for describing and classifying human personality. According to the anthropological and management studies, culture is the integrated system of socially acquired values, beliefs and rules of society (Walle, 2001; Weller and Romney, 1988). Cultural and value distinctions make societies different from one another. Earlier definitions of this term were established late in the Nineteenth Century (Tylor, 1974). Kroeber and Kluckhohn (1952) identified 164 different concepts in the frame of the term. According to anthropological studies, the nature of culture is consisted of diverse elements, such as norms, customs, mores, conventions, language, and religion and so on. Each of these factors plays a substantial role in determining the nature of values. Cultural anthropology looks beyond attempting to perceive how and why peoples of the world differ in disparate ways, as well as, how and why peoples of the world share certain similarities (Serrie, 1986; Ferraro, 2005; Lillis and Tian, 2010).

Therefore, it is assumed as a complex web of norms, values, assumptions, attitudes, and beliefs that are characteristic of a particular group, implying that one way of acting is preferable to another (Walle, 2001; Weller and Romney, 1988; Kuchinke, 1999). Therefore, cultural difference is an important consideration in understanding human behavior. After analyzing the data from more than 40 countries, Hofstede (1980) concluded that these mental programs denote the existence of our underlying value dimensions along which these countries could be positioned into culture areas. Consequently, he identified five dimensions of culture, such as power distance, individualism, masculinity, collectivism, uncertainty avoidance, which provide broad variability of explanations for differences between cultures (Low and Shi, 2002).

Regarding value perceptions of both study populations, this study utilized the following three dimensions: power distance, individualism, and masculinity. Power distance is defined as the extent, to which the less powerful members of organizations and institutions agree that power is distributed unequally. It suggests that a society's level of inequality is endorsed by the followers as much as by the leaders. Power distance index scores are higher for East European, Latin, Asian and African countries and lower for Germanic and English-speaking Western countries (Hofstede, 2009).

Individualism is found within cultures, in which the ties between individuals are loose. Contra this - collectivism, where cultures in which people from birth onwards are integrated into strong, cohesive in-groups, often extended families that continue protecting them in exchange for unquestioning loyalty. Individualism prevails in developed and western countries, while collectivism is common in developing and Asian countries (Hofstede, 2009).

Masculinity versus femininity refers to the distribution of values between the genders, which is another fundamental issue for any society. According to the previous studies masculinity is high in Japan, in German speaking countries, and in some Latin countries like Italy and Mexico. It is low in Nordic countries and in the Netherlands. Hofstede' s value-based cultural dimensions are helpful in identifying both differences and similarities between cultures (Anastasia, Shana, and Leonardo, 2008).

\section{The Relationship Between Personality and Values}

Relatively few studies have attempted to relate personality and values empirically. Recently, studies on both personality and personal values have paid considerable attention on the structure and bases of these constructs. However, few studies have attempted to integrate these advances, either theoretically or empirically, perhaps because they tend to represent discrete streams of research. So far, the majority of studies have been focused on environmental issues rather than endogenous influences on values (Knafo and Schwartz, 2001). But a number of researchers 
around the world have still acknowledged the relationship between personality and values. Rokeach (1973) viewed personality as antecedent to values, which, while stable, can be reprioritized on the basis of experience and social expectations.

The studies of Costa, Terracciano, and McCrae (2001) brought genetics, physiological differences, personality, values, and environmental context together in their Big Five theory of the person. The three core components of the person are basic tendencies, characteristics adaptations, and self concept. Biological bases, external influences, and objective biography are conceptualized as adjoining systems that interact with personality via dynamic processes. In this framework, personal values are prototypical characteristic adaptations, acquired skills, habits, attitudes and relationships that result from the interaction of individual and environment; they are the concrete manifestations of basic tendencies (McCrae and Costa, 1996). Personality, specifically the five high-level domains are endogenous basic temperaments, unaffected by environment.

As a corollary to the authors' findings, personality is endogenous basic temperaments, and based on at least five trends of evidence, such as the remarkable stability of personality across adulthood, the cross-cultural universality of trait structure, theories of bi-ophysiological and neurological bases of dimension confirmed in findings of strong heritability, identification of the same five-factor structure of personality in chimpanzees, and findings of surprisingly weak parental influence on traits (McCrae and Allik, 2002). Thus, in this emerging understanding, values lie at the interface of the environment and endogenous basic temperaments manifested in personality.

\section{Cross-Cultural Study of Personality and Values}

According to Berry (1997), cross-cultural living entails such a transition, where the new context may differ from the previous one physically, politically, socially, as well as culturally. And, the new comers find themselves in a different role. Therefore, they suffer psychological instability, which is termed cultural shock (Oberg, 1960; Blodgett, Lu, Rose, and Vitell, 2001).

Thus, personality concepts are important in every human being, and they clearly can be interesting when comparing personality dimensions across cultures. Questions such as whether the same dimensions exist across nations and whether they are they similarly structured have been asked frequently by anthropologists and cross-cultural psychologists. But recently, researchers have been severely hindered by the lack of an agreed-upon taxonomy of dimensions. It is obviously impossible to conduct cross-cultural studies of each of the 4,000 traits identified by Allport and Odbert (Robbins and Judge, 2009).

Methods of studying cross-cultural differences were discovered by American and western scholars. They used to take samples solely from the western population, using English-language in dimension names (Goldberg, 1994). Hence, it is logical to ask, if it is a roughly western oriented framework, what is its universal application? The instrument has been translated into more than 40 languages, and studies concerning its factors have been conducted in more than 30 countries (McCrae and Allik, 2002). Studies state that one reason for using the same instrument in each case is to find more factors that are definitely absent in the object group. In this sense, the Big Five is a universal model, therefore it can be utilized in cross-cultural studies. But, it does not necessarily mean that there is no additional personality dimension specific to an individual culture (Cheung and Leung, 1998). 


\section{METHOD}

\section{Sample}

In this study the purposive quota sampling method was used. In order to provide balanced findings, an equal number of the study population was selected from three main hospitals from each country, which represent the population. The research tool used was the in-depth interview method for 18 selected interviewees, which consisted of six doctors and three nurses from each side. We chose the subjects by contacting hospital supervisors, which then recommended doctors and nurses for us to interview. Participants for interview were contacted initially by email and telephone calls; subsequently all agreed to participate in interview.

\section{Individual Depth Interview}

Interviews were conducted in two different ways for each country. Interviews for participants from Taiwan were held at a special location that was selected near their work, but for the Mongolians this was held via telephone calls. Interviewees chose the time that would be most suitable for their job schedule. Each interview normally lasted $1 / 3-1 / 2 \mathrm{~h}$, they were taped, and subsequently transcribed. In total, 18 interviews were conducted on both sides. Interviewees were encouraged to narrate the features of their job experience. The authors expressed an interest in the day-to-day practices of managing their job and the personal experiences of the doctors and nurses.

\section{Research Instrument}

In order to provide non-bias within instrument development, eliminate question variability, and establish the variability of reality of answers, we conducted structured interviews. Despite the fact that the cross-cultural model has been applied to over 50 cultures historically, there still should be other features noted such as: faith, politics, languages and other cultural features (Paunonen et al., 1996). The original value and personality dimension module was established in English (McCrae, 2009; Stephanie and Church, 1999). Most staffs of hospitals in Taiwan speak English, but staffs in Mongolian hospitals seldom speak English. Due to that, other two sets of questions were used, one in English; the other Mongolian (Hofstede, 1980; Low and Shi, 2002). Studies suggest that analyzing interview data should avoid bias in interpreting the notes (Creswell, 1998).

In interpreting the data, the study used coding by translating detailed results. Therefore, to simplify the interview results for readers, the authors used the following coding approach to translate the results from the manuscripts, such as A+, A, B+, B, C+, C, D (Weston et al., 2001). From the corresponding interview manuscripts we found many expressions of intermediate or enthusiastic approval by interviewees. The present data for this study had some scores between letters. Thus, we used an intermediate degree $(+)$, where the interview note was within or exceeded points of the ranges in the basic codes. 
TABLE 1

LETTER CODES FOR TRANSLATION OF RESULTS OF INTERVIEW NOTE

\begin{tabular}{|c|c|c|}
\hline Code & Dentition & Key words or phrases code definition from transcripts \\
\hline $\mathrm{A}+$ & $\begin{array}{l}\text { Positive. Any comment indicating evaluation of any aspect of the } \\
\text { receiving and expressing which is explicitly stated as very positive }\end{array}$ & $\begin{array}{l}\text { Key words: good, well, okay, very sure, I do my best; } \\
\text { Positive descriptors: relaxed, happy, motivated; }\end{array}$ \\
\hline A & $\begin{array}{l}\text { Positive. Any comment indicating evaluation of any aspect of the } \\
\text { receiving and expressing which is explicitly stated as positive }\end{array}$ & $\begin{array}{l}\text { Key words: good, well, okay, yes, sure; } \\
\text { Positive descriptors: relaxed, happy; }\end{array}$ \\
\hline $\mathrm{B}+$ & $\begin{array}{l}\text { Positive. Any comment indicating evaluation of any aspect of the } \\
\text { receiving and expressing which is explicitly stated as positive but not } \\
\text { fully. }\end{array}$ & $\begin{array}{l}\text { Key words: good, well, okay, yes, but, I am not sure, } \\
\text { almost; } \\
\text { Positive descriptors: relaxed, happy, moody; }\end{array}$ \\
\hline $\mathrm{B}$ & $\begin{array}{l}\text { Moderate. Any comment indicating evaluation of any aspect of the } \\
\text { receiving and expressing which is explicitly stated as still moderate but } \\
\text { somewhat inclined to negative. }\end{array}$ & $\begin{array}{l}\text { Key words: sometimes, so so, not sure but, not always, } \\
\text { sometimes; } \\
\text { Positive descriptors: Thinking, moody; }\end{array}$ \\
\hline $\mathrm{C}+$ & $\begin{array}{l}\text { Moderate. Any comment indicating evaluation of any aspect of the } \\
\text { receiving and expressing which is explicitly stated as nor positive neither } \\
\text { negative. }\end{array}$ & $\begin{array}{l}\text { Key words: sometimes, so so, not sure but, not always, } \\
\text { sometimes, no, never, how come, almost no; } \\
\text { Positive descriptors: Thinking, moody, shaking head, } \\
\text { unhappy; }\end{array}$ \\
\hline $\mathrm{C}$ & $\begin{array}{l}\text { Negative. Any comment indicating evaluation of any negative aspect of } \\
\text { the receiving and expressing which is explicitly stated as negative }\end{array}$ & $\begin{array}{l}\text { Key words: bad, terrible, no, never, how come; } \\
\text { Negative descriptors: Thinking, shaking head, unhappy; }\end{array}$ \\
\hline $\mathrm{D}$ & Neutral. Neutral comments that are neither positive nor negative. & $\begin{array}{l}\text { Key words: I do not know, I do not care, I am not sure; } \\
\text { Negative descriptors: Thinking, laughing, }\end{array}$ \\
\hline
\end{tabular}

Note. $(\mathrm{A}+)$ refers to very positive, $(\mathrm{A})$ refers to positive, $(\mathrm{B}+)$ refers to still positive but not fully; $(\mathrm{B})$ refers to moderate; $(\mathrm{C}+)$ refers to still moderate but not fully; (C) refers to negative; (D) refers to neutral status.

\section{RESULTS AND DISCUSSION}

\section{Descriptive Statistics}

The total data in this study were collected from 18 persons, to wit three nurses, and six doctors from each country. All nurses were aged below 30, whereas doctors were aged above 40.

\section{Mongolian}

Mongolian side fielded three nurses and six doctors. Two nurses were female, and one was male. All of them have majored in nursing. Their monthly salary was from \$150 to \$200USD. Except one were female doctors. Five of them have master degrees in medical science, while another has a doctoral degree. They were paid from \$220 to \$280USD monthly.

\section{Taiwan}

From Taiwan three nurses and six doctors took part. All of the nurses interviewed in this study were women. Two of them had master degree in the medical field, and were paid \$1,000USD monthly, while another had a bachelor degree, and was paid \$950USD. In totally six doctors were interviewed in this study, one of whom was a woman. One of them had a doctoral degree in medical science, while the other five had master degrees. Interestingly, their wage was notably different. The lowest of them paid was $\$ 1,740$ USD per month, while the highest salary was $\$ 10,580$ USD. 
TABLE 2

INTEGRATED VALUE OF PERSONALITY AND VALUES OF DOCTORS AND NURSES OF MONGOLIA AND TAIWAN

\begin{tabular}{|c|c|c|c|c|c|c|c|c|c|c|c|c|c|c|c|c|c|c|}
\hline \multirow{2}{*}{ No. } & \multicolumn{2}{|c|}{ Nurse1 } & \multicolumn{2}{|c|}{ Nurse2 } & \multicolumn{2}{|c|}{ Nurse3 } & \multicolumn{2}{|c|}{ Doctor1 } & \multicolumn{2}{|c|}{ Doctor2 } & \multicolumn{2}{|c|}{ Doctor3 } & \multicolumn{2}{|c|}{ Doctor4 } & \multicolumn{2}{|c|}{ Doctor5 } & \multicolumn{2}{|c|}{ Doctor6 } \\
\hline & MGL & TW & MGL & TW & MGL & TW & MGL & TW & MGL & TW & MGL & TW & MGL & TW & MGL & TW & MGL & TW \\
\hline Q1 & A & $\mathrm{B}+$ & $\mathrm{B}+$ & $\mathrm{A}$ & $\mathrm{B}+$ & $\mathrm{A}+^{+}$ & $\mathrm{A}+^{+}$ & $\mathrm{A}+$ & $\mathrm{A}+^{+}$ & $\mathrm{B}+$ & $\mathrm{A}+$ & $\mathrm{A}^{+}$ & $\mathrm{B}+$ & $\mathrm{A}+^{+}$ & A & A & A & $\mathrm{A}+$ \\
\hline Q2 & $\mathrm{C}+$ & B & $\mathrm{C}$ & $\mathrm{C}+$ & $\mathrm{C}+$ & $\mathrm{C}$ & $\mathrm{C}$ & $\mathrm{C}+$ & $\mathrm{C}+$ & C & $\mathrm{C}+$ & $\mathrm{C}+$ & B & C & C+ & C & $\mathrm{C}+$ & C \\
\hline Q3 & $\mathrm{A}$ & $\bar{A}$ & $\bar{A}$ & $\mathrm{~B}+$ & B & $\mathrm{A}+$ & $\mathrm{C}+$ & $\mathrm{C}$ & $\mathrm{A}$ & $\mathrm{A}+$ & B & $\mathrm{A}+$ & $\bar{A}$ & $\mathrm{C}+$ & B & $\mathrm{A}$ & A & $\bar{C}$ \\
\hline $\mathrm{Q} 4$ & A & $\mathrm{C}$ & B & $\mathrm{C}+$ & A & A & $\mathrm{B}+$ & $\mathrm{C}$ & $\mathrm{C}$ & $\mathrm{C}$ & B & $\mathrm{C}$ & $\mathrm{C}$ & $\mathrm{B}+$ & $\mathrm{C}$ & $\mathrm{C}$ & $\mathrm{C}$ & $\mathrm{C}$ \\
\hline Q5 & A & B & $\mathrm{B}$ & $\mathrm{B}+$ & $\mathrm{B}+$ & $\mathrm{C}$ & $\mathrm{A}$ & $\mathrm{A}$ & $\mathrm{A}+$ & $\mathrm{C}$ & $\mathrm{A}+$ & $\mathrm{A}+$ & A & B & $\mathrm{B}+$ & $\mathrm{A}+^{+}$ & $\mathrm{B}+$ & A \\
\hline Q6 & A & B & B & $\mathrm{C}+$ & $\mathrm{B}+$ & A & $\mathrm{B}+$ & $\mathrm{C}$ & $\mathrm{B}+$ & A & $\mathrm{B}$ & B & $\mathrm{C}+$ & $\mathrm{B}+$ & $\mathrm{A}$ & $\mathrm{A}$ & A & $\mathrm{A}$ \\
\hline Q7 & A & $\mathrm{C}+$ & $\mathrm{B}+$ & $\mathrm{B}+$ & $\mathrm{C}$ & $\mathrm{C}$ & $\mathrm{C}$ & $\mathrm{A}^{+}$ & $\mathrm{C}$ & $\mathrm{A}+$ & $\mathrm{B}+$ & $\mathrm{C}$ & $\mathrm{B}+$ & $\mathrm{C}$ & $\mathrm{C}+$ & $\mathrm{C}+$ & $\mathrm{C}$ & $\mathrm{C}$ \\
\hline Q8 & $\mathrm{B}+$ & $\mathrm{C}$ & $\mathrm{D}$ & $\mathrm{C}+$ & B + & $\mathrm{A}$ & B+ & $\mathrm{A}$ & $\mathrm{C}$ & $\mathrm{C}$ & $\mathrm{A}$ & $\mathrm{A}^{+}$ & $\mathrm{B}+$ & B & $\mathrm{C}$ & $\mathrm{C}$ & $\mathrm{B}+$ & $\mathrm{C}$ \\
\hline Q9 & $\mathrm{A}$ & $\mathrm{C}$ & A & $\mathrm{A}$ & $\mathrm{C}$ & $\mathrm{C}$ & $\mathrm{C}$ & $\mathrm{A}^{+}$ & $\mathrm{C}$ & $\mathrm{A}$ & B & $\mathrm{B}+$ & $\mathrm{C}$ & $\mathrm{C}$ & B & $\mathrm{B}+$ & $\mathrm{C}+$ & $\mathrm{C}$ \\
\hline $\mathrm{Q} 10$ & $\mathrm{C}$ & $\mathrm{A}$ & A & $\mathrm{B}$ & A & $\mathrm{C}+$ & B & $\mathrm{A}$ & B & $\mathrm{A}+$ & $\mathrm{B}$ & $\mathrm{B}$ & $\mathrm{C}$ & $\mathrm{C}$ & $\mathrm{C}+$ & $\mathrm{A}$ & $\mathrm{B}$ & $\mathrm{A}$ \\
\hline Q11 & A & $\mathrm{A}$ & A & $\mathrm{C}$ & $\mathrm{A}$ & $\mathrm{C}$ & $\mathrm{C}$ & $\mathrm{A}$ & $\mathrm{C}+$ & $\mathrm{A}$ & $\mathrm{B}+$ & A & A & C & $\mathrm{B}+$ & C & $\mathrm{B}+$ & A \\
\hline $\mathrm{Q} 12$ & $\mathrm{C}$ & $\mathrm{A}$ & $\mathrm{C}$ & $\mathrm{C}$ & B & $\mathrm{C}$ & $\mathrm{C}$ & $\mathrm{C}$ & $\mathrm{C}$ & $\mathrm{C}$ & $\mathrm{B}+$ & $\mathrm{B}+$ & $\mathrm{C}$ & $\mathrm{C}$ & $\mathrm{C}$ & $\mathrm{C}$ & A & $\mathrm{C}$ \\
\hline Q13 & C & A & A & $\mathrm{A}$ & $\mathrm{C}+$ & A & $\mathrm{C}$ & A & A & C & $\mathrm{C}$ & B & C & C & A & C & A & A \\
\hline Q14 & A & D & A & A & A & C & A & A & A & A & A & $\mathrm{C}+$ & A & $\mathrm{C}+$ & A & A & A & A \\
\hline Q15 & C & $\mathrm{B}+$ & $\mathrm{D}$ & $\mathrm{D}$ & $\mathrm{C}$ & A & $\mathrm{D}$ & $\mathrm{A}$ & $\mathrm{D}$ & A & A & $\mathrm{D}$ & A & A & $\mathrm{D}$ & $\mathrm{A}$ & A & A \\
\hline
\end{tabular}

Note. Questions for structured interview coded as Q1-Q15.

+ denotes for degree that exceeds the meaning range of code.

\section{Personality Part}

\section{Agreeableness}

Table 2 suggests that generally doctors and nurses of both countries have the same positive personality trending towards agreeableness. According to the results, four of the Taiwanese doctors who are males, as well a female nurse appeared very agreeable to their job, while only three female doctors emerged as very agreeable. This phenomenon can be explained due to the suitable working environment, high payment, or loyalty to the job no matter the environment and social security (Ogoh, 1986; Tsung, 2010). Only one female doctor in Taiwan and one male nurse from Mongolia appeared almost contradictory to agreeableness. They stated that far too much their time is spent at work.

\section{Conscientiousness}

Theories assert that people, who favor conscientiousness, are responsible, dependable, and well organized. They do not engage in risky behaviors (Joshua et al., 2004). From the results in Table 2, it asserts that most of the doctors and nurses from Taiwan and Mongolia are positively to conscientiousness. According to the 22 responses of doctors (eight males and four females doctors from Taiwan; four male and six female doctors from Mongolia) and seven responses from nurses (four Taiwanese females; one male and two Mongolian females), results indicate that they are very conscientious. Four of the Taiwanese interviewees (three female nurses, one female doctor), and seven of the Mongolians (one male and two female nurses, and three female and one male doctor) were moderately so. Finally, according to the data based on 11 responses, which comprises seven doctors (two males and three female doctors from Taiwan; two male doctors from Mongolia), and four nurses (two male and two female nurses from each country) showed responses which mitigated against conscientiousness. 


\section{Openness}

The results of Table 2 show that the majority of interviewees from both countries appear positive to this dimension. It can be explained that staffs in medical service usually become sociable due to job experience. According to the eight responses of doctors (three males and one female doctor from Taiwan; four females from Mongolia) and four responses from nurses (two female Taiwanese; one male and female Mongolian), results indicate that they are just tend to openness. Two of the Taiwanese interviewees (one female nurse, one male doctor), and one female Mongolian doctor had moderate responses. Finally, according to the data based on four responses, which comprises from two doctors (one male doctor from each side), and two female nurses from each country showed responses against openness. People high in openness usually have a range of interests and delight in novelty. But extremely open people commonly appear creative and curious (Joshua et al., 2004).

\section{Neuroticism}

People, who experience neuroticism, usually tend to have negative emotions, such as anger, anxiety, or depression. Those who score highly in neuroticism are emotionally reactive and vulnerable to stress. These problems in emotional regulation can diminish the ability of a person scoring high on neuroticism to think clearly, make decisions, and cope effectively with stress (Robbins and Judge, 2009). According to the 18 responses of doctors (seven male and two female from Taiwan; three males and six females from Mongolia) and nine responses from nurses (two male and one female from Taiwan; two males and four females from Mongolia), results indicate that they do not experience neuroticism. Otherwise they appear emotionally stable. Whereas, 10 responses of doctors (three males and one female from Taiwan; one male and five females from Mongolia), and nine responses of nurses (three females from Taiwan; one male and five females from Mongolia) show experience in neuroticism. But four (three males and one female) responses of Taiwanese doctors showed that they are very experienced in emotional instability. Only a female nurse from Mongolia expressed neutral status.

\section{Extroversion}

Table 2 shows that three doctors (two males and one female) from Taiwan and three responses from nurses (one female Taiwanese, one male and one female Mongolian) appear extroverts. Otherwise, they like where the action is. Whereas, three responses of doctors (one male from Taiwan; one male and one female from Mongolia), and two responses of nurses (one female from both sides) showed that they are not extroverts. In other words, they like to be, and quiet do not often involve themselves in activities. Only a doctor from Taiwan expressed much extroversion. Finally, five doctors (one male from Taiwan; four females from Mongolia) and a female nurse from Taiwan expressed that they are moderately extrovert. From the result we can see that Taiwanese are more predisposed to extroversion. They like sociable activity more than the Mongolians. In particular, Taiwanese male doctors are more extrovert than females; the Mongolians while same sharing the gender ratio, nevertheless, exhibit this trait to a lesser degree than the Taiwanese. 


\section{Value}

\section{Power Distance}

Studies have defined that power distance is the extension to which a society accepts that power in institutions and organizations is distributed unequally (Ana, Minoo, and Aviv, 2007). We can see from Table 2, which asserts that most of the doctors and nurses from Mongolia have more experience in power distance than Taiwanese. From 11 responses of doctors (three males and two females from Taiwan; one male, five females from Mongolia) and five responses from nurses (two female Taiwanese; one male and two female Mongolians), results suggested that they have experienced a power distance environment. According to the data based on 13 responses from doctors (six males and one female from Taiwan; one male and five females from Mongolia), and six from nurses (four females from Taiwan; two females from Mongolia) it was expressed that they do not feel power distance. One male nurse from Mongolia was moderate having sometimes experienced power distance. From these results we can conclude that the Mongolian participants, specially, women feel more power distance than Taiwanese, whereas Taiwanese men experience much less power distance.

\section{Individualism}

As indicated in Table 2, 15 doctors (five males and one female from Taiwan; one male and eight females from Mongolia), and eight responses from nurses (four females from Taiwan; two males and two females from Mongolia) were experienced in individualism. Whereas, eight responses of doctors (four males and one female from Taiwan; one male and two females from Mongolia), and three responses of nurses (one female from Taiwan; one male and one female from Mongolia) showed that they are not individualistic. Only a male doctor from Taiwan expressed a moderate feeling towards this. Theories suggest that individualism is the degree to which people prefer to act as individualistic rather than as team (Ana et al., 2007). Based on the results from Table 2, we can assume that Taiwanese like to work as a team, while Mongolians have an individualistic manner in work. In particular, the present study shows that Mongolian female doctors were more individualistic, while Taiwanese male doctors appeared comparatively so more than women.

\section{Masculinity}

Recent studies assert that masculinity is a national culture attribute that describes the extent to which the culture favors male domination roles of achievement, power, and control (Low and Shi, 2002). Data results affirm that majority of interviewees from both countries prefer masculinity. According to their explanation, men seem to find communication easier than women. From eight responses of doctors (three males and two females from Taiwan; three females from Mongolia) and two female nurses from Taiwan, it can be seen that men find communication more preferable than women. And only two nurses (one male and one female) from Mongolia coded negatively in their tendency of communication with men. Eventually, one male doctor and one female nurse from Taiwan, as well as, three female doctors and one female nurse from Mongolia noted a neutral response. But after deliberate interview, it is revealed that sex had nothing to do with communication for them.

Results demonstrate that most of the doctors of both countries prefer male supervisors when in communication as they find them easier to understand both with each other and in the working 
environment. Interestingly, most of the Mongolians, who preferred male, were female doctors, while the majority of Taiwanese doctors were male.

\section{CONCLUSION AND LIMITATION}

In conclusion, we found that there are differences in personality and values between doctors and nurses of Mongolia and Taiwan caused by distinct factors. In exploring the cross-cultural differences, we perceived that personality and values were not only influenced by tradition, culture, and nationality, but were also strongly impacted by social security, working environment, and satisfaction from life and job (Hofstede, 2001).

\section{Personality}

Results manifest that doctors and nurses of both countries appear agreeable. It does not mean that personality and values of those people are the same. Rather, it can be said for Taiwan that their high satisfaction is attributable to a suitable working environment, high payment, and high motivation (Elizabeth and Adelina, 2006) toward to job performance (Ogoh, 1986; Tsung, 2010). On the other hand, those things favored by Taiwanese doctors and nurses, do not exist for the Mongolian healthcare staffs. The authors found the answer to the question - "why are healthcare staffs in the Mongolia agreeable?" The answer is - they are agreeable to their job. The reason is that, in spite of lack of social security, they get satisfaction and motivation when the patients get better, or their recommended treatments are successful (from interviews with doctors and nurses of Mongolia).

This study found differences of conscientiousness between doctor and nurses of both countries. Joshua et al. (2004) argues that people who score high in conscientiousness are responsible, dependable, well organized, and they are less involved with risky behaviors. Findings prove that Taiwanese doctors and nurses are more conscientious than the Mongolians. But the Mongolian doctors still fit into this category. Specially, male doctors and female nurses scored high in this. Therefore, we conclude that the management philosophy of Taiwan is more punctual and strict than the management in Mongolia, where there is still some influence from Russia and traditional Buddhism. Second, gender characteristics in the occupational area also influence work attitudes. According to the results, male doctors and female nurses are more conscientiousness. Third, salary impacts the differences between the two countries, which lead to more conscientiousness in the Taiwanese participants.

According to the openness dimension, representatives of both countries scored equally positively. The only difference detected in gender was that Taiwanese men were found high in openness, while Mongolian women scored highly. From one side it can be explained that staffs in the service line usually are sociable due to the job requirement and experience (John and Srivastava, 1999). On the other hand, differences emerge between genders. It is truly related to culture difference issues. Therefore, it is concluded that according to Mongolian culture, men prefer philosophy "talk less, do more" (Baabar, 2000). It does not mean that Taiwanese male doctors are less do and more talk. Essentially, the Mongolian men are less talkative. We can conclude that the social development process impacts personalities differently (Steven, Emma, and Ara, 2006). It shows that Taiwan is a country with high social development comparative to Mongolia. (World Bank. (2010). Report of GDP of countries. Retrieved from http://web.worldbank.org/WBSITE/EXTERNAL/COUNTRIES/EASTASIAPACIFICEXT/MO NGOLIAEXTN/0,,menuPK:327734 pagePK:141132 piPK:141109 theSitePK:327708,00.html). 
Generally, it seemed that Taiwanese people have already learned communication skills. According to population size and social development, Mongolia is at an earlier stage of development. Thus, we conclude that culture and social development difference impacts personalities differently.

Studies discovered that those, who score highly in neuroticism are emotionally reactive and find many situations stressful (Hofstede, 2001). In the area of neuroticism we found significant differences between both countries. Results state that the Mongolian interviewees scored high in neuroticism, while the Taiwanese scored much lower. However, most of the Mongolian doctors were female doctors, who were above 40 , whereas most of the high evaluating participants in neuroticism from Taiwan were male doctors, who were above age 40 . Therefore, it can be concluded that, the persons who are more sociable are more neurotic. Second, it is noticeable that those who scored high in this dimension were over 40 years old. Third, most of them were doctors. Therefore, we concluded that this resulted according to a culture difference related to gender characteristics, age, and occupational attributes (Elizabeth and Adelina, 2006).

Findings demonstrate that Taiwanese male respondents were mostly agreeable, sociable, and conscientiousness. In examining these traits, we found that Taiwanese participants, particularly doctors, are more extrovert than the Mongolians. Further, we observed that male doctors from both countries are more extroverted than females. Consequently, we conclude that Taiwanese doctors have high motivation in doing their job. The main reasons are high payment and management culture characteristics. The second most common thing that happened in respect to the gender aspect is that male doctors were more inclined to leadership roles and social dominance (Robbins and Judge, 2009).

\section{Value}

According to the results, most of the doctors and nurses from Mongolia experience more in power distance than Taiwanese. Particularly, the Mongolian female participants experience more distance in power. This is a common phenomenon in Mongolian society since women usually take charge of their family (Baabar, 2000). The population of Mongolia is comparatively small in relation to territorial size and the majority of the population is female. Because of that, social problems have brought a lot of stress and pressure on women, both from life and working environment. Another problem is that the social security and low wages have caused low living standards, which leads to dissatisfaction. Third, there still exists a bureaucrat management system, established during the communist period in Mongolia. Therefore, we concluded that the power distance experienced is high in Mongolia because of the social and life pressure for women, low payment, and uncomfortable management system.

Recent studies suggest that eastern cultures appear more collectivistic, whereas western countries, especially the Americans scored high in individualism (Ana et al., 2007). As the authors postulated in this study, Mongolia is a half westernized Asian country (Bor, 2000). Results of this paper showed it. Findings demonstrate that Taiwanese participants like to work as a team, while the Mongolians have a more individualistic manner in their work. Especially, the present study shows that Mongolian women doctors were more individualistic, while Taiwanese male doctors appeared comparatively higher than their women. Thus, the conclusion asserts that the shaped distinction to Mongolia is caused by a monopolized and centralized management system of over 70 years during the communist period, which made people executives but not initiative driven (Baabar, 2000; Bor, 2000). While results from Taiwan can be attributed to the typical Asian collectivistic culture (Chow et al., 2002). 
Researchers assert that masculinity is high in countries such as Japan and Korea (Low and Shi, 2002; Anastasia et al., 2008; Kuchinke, 1999). Participants of both countries expressed preference in communicating with males than women in the working environment. Moreover, a majority of participants from Mongolia noted communication with supervisors had nothing to do with the supervisors' gender, while few of Taiwanese responded in the same way. According to the results, the authors conclude that in the management field, men are preferred over women in both countries. Lastly, there are still people on both sides, who do not care about gender in communication. According to their explanation they prefer how people communicate rather than gender.

In summary, we conclude that besides personality and values, there are several factors, which make the participants of both countries behave differently. According to the results of our study, gender differentiates both the aspects of dimension and culture of both countries. Another significant factor is payment. It can be one of the main factors of differentiation between the two countries. Because of the differences in income level, personality facets differed. Occupation and age appear as the emerging factors for participants of both countries. As discussed before, the doctors were different in some aspects of personality and values. Specifically, neuroticism and extraversion considered as one of the dimensions affected most by occupation. In addition, more secondary factors observed during this study, such as nomadic lifestyle, affects from the Soviet Union, gender inequality, social pressure, as well as Asian culture. All except the last factor were related to Mongolia, which made Mongolian society and individuals prone to more stress, a large power distance oriented management system, and individualism (Baabar, 2000). Researchers argue that Taiwanese management philosophy is a mix of three components (Chow et al., 2002; Chong, 2008; Low and Shi, 2002). Asian culture reflects on the management philosophy of Taiwan. However, Taiwan adopted democratic rules mainly from the United States after decades of being under Japanese rule; the basic management philosophy is still Chinese Confucianism. Thus, Taiwanese management culture can be assumed as a complex system of culture from America and Japan, centered around a strong Confucian component.

\section{Limitations}

This study has several limitations. First, in this study we used the telephone call interview method. Therefore, we suggest future studies use the quantitative method to obtain more deliberate data for a more comprehensive study. Because of the distance between the two countries, sample populations were chosen from one hospital of each country. Thus, for future studies it is advised that a wider population range be selected. Third, the sample population of this paper consisted of two sub-groups: nurses and doctors. Consequently, it is suggested that more classifications in sample populations be used for future studies.

\section{Managerial Implications}

A bilateral co-operation between Taiwan and Mongolia has been developed in trade, educational, and humanitarian fields since 2000. Scientifically, the management issues are divided into two general categories of eastern or team work philosophy, and western or individualistic philosophy. Both of them have advantages and disadvantages. In the case of this study, we should note that Taiwanese prefer to work as a team, and this kind of management style is more suitable for them.

The Mongolians are more individualistic, as such, firms or organizations should be careful in establishing the project team members and leaders. Both sides have the same preference towards 
the gender aspect. They prefer men more than women in dealing with the management problems. But, this can lead to some trouble in balancing the gender consistency. Results of the study showed the power distance in the Mongolian team was high, which makes them complicated in communication, while Taiwanese experienced this to a lesser degree. The authors suppose that this is detrimental to management, especially in decision making. Project leaders and members should adjust communication with the Mongolians. Otherwise, misunderstandings, or some other barriers may then occur in managing a project.

As the results of our study show, we can see that Taiwanese project team members are fortunate in their working environment, and often benefit from a good insurance policy, and high payment. The Mongolians however, have a poor environment and low salary, their productivity is high, and motivation for work is the same as the Taiwanese. Therefore, we imply that the Mongolians are as reliable and loyal to their job as the Taiwanese. It is also observed that Mongolian management is more flexible. The Taiwan team members were too punctual. They tend to think that a problem has to be solved by a definite given way. But the Mongolians look for alternative ways of solving a problem. We think this is the consequence of their nomadic culture of survival. But we should highlight the punctuality of the Taiwanese as a positive.

Finally, both sides should notice that Taiwanese men are more open that the Mongolians. Corporations should pay attention to that, during negotiations it might be that the Mongolian side is less prone to talking. So, this does not really mean that the Mongolian side is reluctant in concluding agreements. Instead, the opposite side should be more initiative.

\section{ACKNOWLEDGEMENTS}

The authors thank to the colleagues of the Central Hospital of Mongolia and China Medical University Hospital of Taiwan, who helped in gathering data, as well the native-English speaking teachers of International College of Asia University for their professional editing of this paper. The authors also thank the editors and reviewers of IJBA for their critic comments and constructive suggestions. Munkh-Ulzii Batmunkh is the Corresponding author; he can be reached by email at: ulzii03@gmail.com.

\section{REFERENCES}

Abrams, D., Ando, K., and Hinkle, S. (1998). Psychological Attachment to the Group: Cross Cultural Differences in Organizational Identification and Subjective Norms as Predictors of Workers' Turnover Intentions. Personality and Social Psychology Bulletin, 24, (10), 1027-1040.

Alden, D. L., Wayne, Hoyer, D., and Chol, L. (1993). Identifying Global and Culture-Specific Dimensions of Humor in Advertising. A Multinational Analysis. Journal of Marketing, 57, (2), 64-75.

Anastasia, G., Shana, D., and Leonardo, L. (2008). Software of the Mind - A Review of Applications if Hofstede's Theory to IT Research. Journal of Information Technology Theory and Application, 9, (3), 1-37.

Ana, M. S., Minoo, F., and Aviv, S. (2007). Hofstede's dimension of culture in international culture in international marketing studies. Journal of Business Research, 60 , (2), 277-284. 
Anonymous. (1240). The Secret History of the Mongols. Dolo` anboldag of Koede`e-aral on the Kelueren.

Baabar, B. (2000). Nuudel Suudal.Ulaanbaatar, Ulaanbaatar, Mongolia: Admon.

Battiste, M., and James, Y. (2002). Indigenous Knowledge and Heritage: A Global Challenge, Sage Publications, London.

Bayarkhuu, D. (October, 2010). Talk after having being cultured. The News. Retrieved on October 30, 2010 from http://bayarkhuu.niitlelch.mn/content/2562.shtml

Bernhard, W. (2009). Impact of globalization on human work. Safety Science, 47, (6), 723-902. Berry, J. W. (1997). Immigration, acculturation, and adaptation. Applied Psychology, 46, (1), 534.

Blodgett, J. G., Lu, L. C., Rose, G. M., and Vitell, S. J. (2001). Ethical Sensitivity to Stakeholder Interests: A Cross-Cultural Comparison. Journal of the Academy of Marketing Science, 29, (2) 190-202.

Bor, J. (2000). History of Diplomatic Relations of Mongol-Eurasia. Ulaanbaatar, Mongolia: Admon.

Bronfenbrenner, U. (1979). The ecology of human development: Experiments by nature and design, MA: Harvard University Press.

Butcher, J. N., Lim, J., and Nezami, E. (1998). Objective study of abnormal personality in crosscultural settings. The Minnesota Multiphasic Personality Inventory (MMPI-2). Journal of CrossCultural Psychology, 29, (1), 189-211.

Chang, E. (2003). Composite effects of extrinsic motivation on work effort: case of Korean employees. Journal of World Business, 38, (1), 70-79.

Cheung, F. M., and Leung, K. (1998). Indigenous Personality Measures. Journal of Cross Cultural Psychology, 29, (1), 233-248.

Chong, E., and Hoecklin, L. (2008). Managerial competency appraisal: A cross-cultural study of American and East Asian managers. Journal of Business Research, 61, (3), 191-200.

Chow, C. W., Harrison, G. L., McKinnon, J. L., and Wu, A. (2002). The organizational culture of public accounting firms: evidence from Taiwanese local and US affiliated firms. Accounting, Organizations and Society, 27, (4/5), 347-360.

Costa, P. T., Jr., Terracciano, A., and McCrae, R. R. (2001). Gender differences in personality traits across cultures: Robust and surprising findings. Journal of Personality and Social Psychology, 81, (2), 322-331. 
Creswell, J. W. (1998). Qualitative inquiry and research design: Choosing among five traditions. Thousand Oaks: Sage.

Duncan, M. K. W., and Blugis, A. (In Press). Maslow`s Needs Hierarchy as a Framework for Evaluating Hospitality Houses' Resources and Services Original Research Article. Journal of Pediatric Nursing. Retrieved on June 03, 2010 from http://www.sciencedirect.com/science? ob=ArticleURL\& udi=B6WKM-50819NW$2 \&$ user $=2459929 \&$ coverDate $=06 / 07 / 2010 \&$ rdoc $=1 \&$ fmt $=$ high \& orig $=$ search \& origin $=$ sear ch\& sort $=\mathrm{d} \&$ docanchor $=\& v i e w=\mathrm{c} \&$ searchStrId $=1521811993 \&$ rerunOrigin $=$ google $\&$ acct $=$ C000057331\& version $=1 \&$ urlVersion $=0 \&$ userid $=2459929 \& \mathrm{md} 5=0 \mathrm{f} 87 \mathrm{ee} 1 \mathrm{~b} 72964 \mathrm{c} 349 \mathrm{~b} 130 \mathrm{a}$ $\underline{8 \mathrm{~d} 3 \mathrm{~d} 8 \mathrm{bd} 17 \mathrm{a} \& \text { searchtype }=\mathrm{a}}$

Elisabeth, G., and Lise, K. (2001). The doctor-nurse relationship: how easy is it to be a female doctor co-operating with a female nurse? Social Science and Medicine, 52, 189-202.

Elizabeth, P., and Adelina, B. (2006). Job motivation and satisfaction: Unpacking the key factors for charity shop managers. Journal of Retailing and Consumer Services, 13, (2), 121-131.

Emery, C. R., Tian, R. G., and Witte, E. M. (2002). "The effect of cultural differences on effective advertising: A comparison between China and the U.S.," Proceedings: Decision Science Institute (DSI), Southeastern Region, 37-40. Hilton Head, SC.

Erchak, G. M. (1998). The Anthropology of Self and Behavior. Rutgers University Press, New Brunswick, New Jersey.

Fanon, F. (1952). Black Skins White Masks. New York: Grove.

Ferraro, G. P. (2005). The Cultural Dimension of International Business. $5^{\text {th }}$ Ed., Pearson Prentice Hall, Upper Saddle River, New Jersey.

Geertz, C. (1973). The Interpretation of Culture. Basic Books. New York.

Goldberg, L. R. (1994). The development of markers for the Big-Five factor structure. Psychological Assessment, 4, (1), 26-42.

Gregory, G. D., and Munch, J. M. (1997). Cultural Values in International Advertising: An Examination of Familial Norms and Roles in Mexico. Psychology and Marketing, 14, (2), 99119.

Hoecklin, L. (1996), Managing Cultural Differences: Strategies for Competitive Advantage, Addison-Wesley, Wokingham.

Hofstede, G. (1980). Culture Consequences: International Differences in Work-related Values, Sage Publications, London. 
Hofstede, G. (2001). Culture's consequences: Comparing values, behaviors, institutions, and organizations across nations. (2nd ed.). Thousand Oaks, CA: Sage.

Hofstede, G. (2009). Dimensionalizing Cultures: The Hofstede Model in Context. Online Readings in Psychology and Culture (Unit 17, Chapter 14), International Association for CrossCultural Psychology, Universities of Maastricht and Tilburg, The Netherlands.

Jackson, P. (2000). The Mongol Empire, 1986-1999 Original Research Article. Journal of Medieval History, 26, (2), 189-210.

Joshua, D. M., Donald, L., Rick, S. Z., Logan, T. K., Carl, K., and Clayton, R. (2004). The utility of the Five Factor Model in understanding risky sexual behavior. Personality and Individual Differences, 36, (7), 1611-1626.

John, O. P., and Srivastava, S. (1999). The Big-Five Trait Taxonomy: History, Measurement, and Theoretical Perspectives. In L. A. Pervin and O. P. John (Eds.), Handbook of personality: Theory and research, 2, 102-138, New York: Guilford Press.

Iqbal, T. M., and Elmallah, A. A. (1997). International accounting: a global perspective. SouthWestern College Publishing, Cincinnatti.

Katigbak, M. S., Church, A. T., Guanzon-Lapeña, M. A., Carlota, A. J., and del Pilar, G. H. (2002). Are indigenous personality dimensions culture specific? Philippine inventories and the five-factor model. Journal of Personality and Social Psychology, 82, (1), 89-101.

Kevin, A., and Black, P. (1993). Conflict resolution in intercultural settings: Problems and Prospects. In: Conflict Resolution Theory and Practice: Integration and Application. Sandole, D.J.D. and H. van der Merwe (Eds.). Manchester University Press, Manchester, England.

Knafo, A., and Schwartz, S. H. (2001). Value socialization in families of Israeli-born and Sovietborn adolescents in Israel. Journal of Cross-Cultural Psychology, 32, (2), 213-228.

Koltko-Rivera, M. E. (2006). Rediscovering the Later Version of Maslow`s Hierarchy of Needs: Self-Transcendence and Opportunities for Theory, Research, and Unification Original Research Article. Review of General Psychology, 10, (4), 302-317.

Kroeber, A. L., and Kluckhohn, C. (1952). Culture: A Critical Review of Concepts and Definitions, The Museum, New York.

Kuchinke, K. P. (1999). Leadership and culture: Work-related values and leadership styles among one company's U.S. and German telecommunications employees. Human Resource Development Quarterly, 10, (2), 135-154.

Lazarus, R. S., and Folkman, S. (1984). Stress, appraisal, and coping. New York: McGraw-Hill. 
Lillis, M. P., and Tian, R.G. (2009). Cross-cultural communication and emotional intelligence. Marketing Intelligence and Planning, 27, (3), 428-438.

Lillis, M. P., and Tian, R. G. (2010). Cultural Issues in the Business World: An Anthropological Perspective. Journal of Social Sciences, 6, (1), 99-112.

Low, S., and Shi, Y. (2002). An exploratory study of Hofstede's cross-cultural dimensions in construction projects. Management Decision, 40, (1), 7-16.

Marrewijk, A. V. (2010). European Developments in Business Anthropology. International Journal of Business Anthropology, 1 (1), 26-44.

Mariampolski, H. (2005). Ethnography for Marketers: A Guide to Consumer Immersion. Sage Publications, Newbury Park, CA., ISBN: 10: 0761969470.

Maslow, A. (1968). Toward a Psychology of Being. Second edition. New York: Van Nostrand Reinhold Co.

McCarty, J. A., and Hattwick, P. M. (1992). Cultural Value Orientations: A Comparison of Magazine Advertisements from the United States and Mexico. Advances in Consumer Research, $19,(2), 34-38$.

McCrae, R. R., and Costa, P. T. (1990). Personality in adulthood. New York: The Guildford Press.

McCrae, R. R., and John, O. (1992). An introduction to the five-factor model and its applications. Journal of Personality, 60, (2), 174-214.

McCrae, R.R. and Costa Jr., P.T., (1996). Toward a new generation of personality theories: theoretical contexts for the five-factor model. In: Wiggins, J.S., Editor, 1996. The five factor model of personality. The Guilford Press, New York.

McCrae, R. R., Herbst, J. H., and Costa, P. T., Jr. (2001). Effects of acquiescence on personality factor structures. In R. Riemann, F. M. Spinath, and F. Ostendorf (Eds.), Personality and temperament: Genetics, evolution, and structure (pp. 217-231). Berlin, Germany: Pabst Science Publishers.

McCrae, R. R., and Allik, J. (Eds.). (2002). The Five-Factor Model of Personality across Cultures. New York: Kluwer Academic/Plenum Publishers.

McCrae, R. R., and Costa, P. T., Jr. (2003). Personality in adulthood: A Five-Factor Theory perspective (2nd ed.). New York: Guilford.

McCrae, R. R. (2009). Cross-Cultural Research on the Five-Factor Model of Personality (Version 2). Online Readings in Psychology and Culture (Unit 6, Chapter 1/V2). International Association for Cross-Cultural Psychology. Retrieved on April 09, 2010, from 
http://orpc.iaccp.org/index.php?option=com_content\&view $=$ article\&id=100:mccraev $2 \&$ catid $=24$ :chapter\&Itemid $=15$

Morden, T. (1999). Models of National Culture - Management Review. Cross Cultural Management, 6, (1), 19-44.

MunkhDalai A., Zhang, E. B., and Huiping, Z. (2007). Mongolia nomadic culture and ecological culture: On the ecological reconstruction in the agro-pastoral mosaic zone in Northern China Original Research Article. Ecological Economics, 62, (1), 19-26.

National Statistical Office of Mongolia. (2010). Monthly Bulletin of Statistics. Retrieved on May 07, 2010 from http://www.nso.mn/v3/index2.php?page=free access

Oberg, K. (1960). Culture shock: Adjustment to new cultural environments. Practical Anthropology, 7, (4), 177-182.

Ogoh, A. S. (1986).The political economy of doctors' strikes in Nigeria: A Marxist interpretation. Social Science and Medicine, 22, (4), 467-477.

Paunonen, S. V., Keinonen, M., Trzebinski, J., Forsterling, F., Grishenko-Roze, N., Kouznetsova, L., and Chan, D. W. (1996). The structure of personality in six cultures. Journal of CrossCultural Psychology, 27, (3), 339-353.

Peters, T. J., and Waterman, R. H. (1982). In search of excellence : lessons from America's bestrun companies. New York, London: Harper and Row.

Pratt, J., Mohrweis, L. C., and Beaulieu, P. (1993). The interaction between national and organizational culture in accounting firms: an extension. Accounting, Organizations and Society, $18,(7 / 8), 621-628$.

Roth, M. S. (1995). The Effects of Culture and Socioeconomics on the Performance of Global Brand Image Strategies. Journal of Marketing Research, 32, (2), 163-175.

Robbins, S. T., and Judge. (2009). Organizational behavior. Prentice Hall.

Richard, De S., and Marjot, J. (1961). Doctor-nurse relationships in a hospital environment. The Lancet, 278, (7218), 1448-1450.

Rokeach, M. (1973). The nature of human values. The Free Press, New York.

Sabine, G., Chris, B., and Dierckx de, C. (2010). Nurses' ethical reasoning and behavior: A literature review. International Journal of Nursing Studies, 47, (5), 635-650.

Salier, R. (2009). Personal communication with Dr. Robert Tian, cited in: Lillis, M. P., and Tian, R. G. (2010). Cultural Issues in the Business World: An Anthropological Perspective. Journal of Social Sciences, 6, (1), 99-112. 
Schmitt, D. P., Allik, J., McCrae, R. R., and Benet-Martínez, V. (2007). The Geographic Distribution of Big Five Personality Traits: Patterns and Profiles of Human Self-Description Across 56 Nations. Journal of Cross-Cultural Psychology, 38, (2), 173-212.

Schein, E. H. (1993). Organizational Culture and Leadership. 2nd Ed., Jossey-Bass.

Schlereth, T. J. (1999). Material Culture Studies in America, 1876-1976. AltaMira Press, Oxford.

Serrie, H. (1986). Anthropology and International Business. College of Williams and Mary, Williamsburg, VA.

Sibuet, J. C., and Hsu, S. H. (2004). How was Taiwan created? Tectonophysics, 379, (1/4), 159181.

Smith, L. (1999). Decolonizing Methodologies. London: Zed.

Soeters, J., and Schreuder, H. (1988). The interaction between national and organizational cultures in accounting firms. Accounting, Organizations and Society,13, (1), 75-85.

Soutar, G. N., Grainger, R., and Hedges P. (1999). Australian and Japanese Value Stereotypes: A Two Country Study. Journal of International Business Studies, 30, (1), 203-217.

Stephanie, D., G., and Church, A. T. (1999). A Cross-Cultural Study of Response Biases in Personality Measures. Journal of Research in Personality, 33, (4), 415-441.

Steven, J. H., Emma, E. B., and Ara, N. (2006). What do Cross-National Comparisons of Personality Traits Tell Us? International Journal of Cross Cultural Management, 6 (2), 243-266.

Terracciano, A., and McCrae, R. R. (2006). Cross-Cultural Studies of Personality Traits and their Relevance to Psychiatry. Epidemiol Psichiatr Sociology, 15, 176-184.

Toby, G., Bonnie, S., Jackie, W., Roland, P., and Brenda, L. (2003). Paying doctors by salary: A controlled study of general practitioner behavior in England. Health Policy, 64, (3), 415-423.

Tomas, D. C., and Inkson, K. (2004). Cultural Intelligence: People Skills for Global Business. $4^{\text {th }}$ Edn., San, Fransisco, CA: Berrett-Koehler Publishers, Inc.

Triandis, H. C. (1972). The Analysis of Subjective Culture: An Approach to Cross-Cultural Social Psychology. John Wiley and Sons Inc., New York.

Trice, H. M., and Beyer, J. M. (1993). The Cultures of Work Organizations. Prentice Hall, Inc., Englewood Cliffs, New Jersey.

Tsung, O. C. (2010). Chinese medical doctors' salaries. International Journal of Cardiology, 138, (1), 1-108. 
Tylor, E. B. (1974). Primitive Culture: Researches into the Development of Mythology, Philosophy, Religion, Language, Art and Custom. Gordon Press, New York.

Tyus, C. N., Gibbons, C., Robinson, K. A., Twose, C., and Guyer, B. (2010). In the shadow of academic medical centers: A systematic review of urban health research in Baltimore city. Community health, 35, (4), 433-452.

Vitell, S. J., Nwachukwu, S. L., and Barnes, J. H. (1993). The Effects of Culture on Ethical Decision-Making: An Application of Hofstede's Typolog. Journal of Business Ethics, 12, (10), 753-760.

Walle, A. H. (2001). Qualitative Research in Intelligence and Marketing. Quorum Books, Westport, CT.

Walle, A. H. (2010). Indigenous People and Human Resource Management. International Journal of Business Anthropology, 1, (1), 95-114.

Weller, S., and Romney, A. K (1988). Systematic Data Collection. 1st Edn., Sage Publications, Newbury Park, CA.

Weston, C., Gandell, T., Beauchamp, J., McAlpine, L., Wiseman, C., and Beauchamp, C. (2001). Analyzing Interview Data: The Development and Evolution of a Coding System. Qualitative Sociology, 24, (3), 381-400.

World Bank. (2007). Mongolia Country Economic Memorandum, Washington DC.

World Bank. (2010). Quarterly report. Retrieved on October 11, 2010, from http://web.worldbank.org/WBSITE/EXTERNAL/COUNTRIES/0, pagePK:180619 theSitePK:1 $\underline{36917,00 . h t m l}$

World Bank. Report of GDP of countries. Retrieved on October 13, 2010 from http://web.worldbank.org/WBSITE/EXTERNAL/COUNTRIES/EASTASIAPACIFICEXT/MO NGOLIAEXTN/0,,menuPK:327734 pagePK:141132 piPK:141109 theSitePK:327708,00.html Wright, S. (1994). Anthropology of Organizations. Routledge, New York.

Zandpour, F. V., Campos, J., Catalano, C., Chang, Cho, Y. D., Hoobyar, R., Jiang, S., Lin, M., Madrid, S., Scheideler, H., and Osborn, S. T., (1994). Global Reach and Local Touch: Achieving Cultural Fitness in TV Advertising. Journal of Advertising Research, 34, (5), 35-63. 